\title{
Forest technicians' associations in Canada
}

The Society of American Foresters recently aired a discussion in the Journal of Forestry dealing with the problem of membership for Forest Technicians - contrasting the advantages of a membership category for Forest Technicians within the Society to encouragement of a separate technician association. A subsequent SAF referendum has authorized a non-voting forest technician membership category. This has apparently been done without a great deal of reference to forest technicians themselves, and it remains to be seen what response will result.

Forest technicians in Canada have demonstrated a greater propensity to form organizations of their own, and have been generally reluctant to join the Canadian Institute of Forestry as non-voting Affiliates. There are presently four societies of forest technicians in Canada, and two more-restricted associations of forest officers. These suggest that many Canadian forest technicians are interested in developing an identity of their own.

The oldest of these is the Nova Scotia Forest Technicians Association, established in 1964. It now has a membership of approximately $150 \mathrm{com}$ pared to a membership of about 50 in the Nova Scotia Section of the CIF. The Forest Technicians Association has shown itself to be an active and responsible group. Regard for its responsibility was reflected in 1966 when the Deputy Minister of Lands and Forests observed that forest technicians were in close daily contact with forest workers and the general public and therefore the Association's views on various forestry matters and problems would be of interest to the Department. Close liaison is maintained between the technical and professional organizations and a cordial relationship exists in an atmosphere of mutual respect. The existence of separate but allied organizations seems to be working well.

Forest technicians in Ontario were the next group to organize and have adopted the broader name of The Association of Natural Resources Technicians of Ontario. Dating from 1968, this Association had a 1970 membership of approximately 265 and may soon surpass the Ontario CIF membership by a significant margin. Its aims are to promote the knowledge, skill, and proficiency of its members in matters relating to management of renewable natural resources of the Province and to achieve recognition of members' role in resource management. The Association is now understood to be in the process of applying for a Provincial Charter.

In Western Canada, the formation of technicians' associations is a relatively recent development. The Forest Technologists' Association of British Columbia was established in 1969, almost simultaneously with a similar but separate group in Alberta. The objectives of these organizations are generally to maintain standards, and to promote and increase proficiency of their members. Membership of both groups is based on the two-year Forest Technology program as standard, with alternate classes of membership open to graduates of other programs, or nongraduates working as technicians. Membership figures for these newer organizatoins are lower than the Nova Scotia and Ontario groups, the B.C. group having 36 active, 29 associate and 20 student members, and Alberta having 24 members. These also contrast to the CIF membership figures which total 509 in five British Columbia sections and 96 in Alberta. The B.C. membership includes 56 in the affiliate category, some of whom could be technicians. There are 14 affiliate CIF members in Alberta, only two of whom would qualify for membership in the technicians' association. It is expected that membership in the technician organizations will increase, and will likely surpass the CIF membership.

Training of technicians in both western provinces was first undertaken by provincial forest services through one-year in-service programs. An interesting development related to this is formation of two societies of Forest Officers - the first in British Columbia in 1960, and an Alberta group in 1970. Membership in these is open generally to technicians holding Forest Officer positions. The British Columbia Society has 187 members representing approximately $96 \%$ of the total potential. The Alberta group is still in the formative stage with 80 members representing approximately $33 \%$ of those eligible.

Most members of the two societies of Forest Officers would also qualify for some category of membership in the technicians' associations. A few Alberta technicians belong to both groups, while discussions among the B.C. organizations are pursuing this possibility. It will be interesting to see how much intermingling actually results.

The formation of these groups indicates that forest technicians do have their own desire for identity, and have interests of their own within the broad scope of the forestry field.

H. W. Blenis, Maritime Forest Ranger School Fredericton, N.B. P. J. Murphy, Forest Technology School Hinton, Alberta 